\title{
Prevalence of a virus similar to human hepatitis B virus in swine
}

Wengui Li ${ }^{1,2}$, Ruiping She ${ }^{1 *}$, Liqiang Liư ${ }^{3}$, Hua You', Jun Yin ${ }^{1}$

\begin{abstract}
Background: The objective of this study is to established evidence of the existence of a novel member of the hepadnavirus family endemic in swine. Temporarily this virus was designated as swine hepatitis B virus (SHBV). This SHBV can be detected by using human hepatitis B virus diagnostic kits including ELISA, immunohistochemical staining, and transmission electron microscopy (TEM). Also seroprevalence of pig farms in Beijing, China, and pathological features of SHBV infection was determined.

Results: Screened result shows that overall prevalence of HBsAg was $24.8 \%$, closed to that of anti-HBsAg, whereas $\mathrm{HBeAg}$ and anti-HBe were barely detectable. The distribution of HBsAg and HBcAg was examined by immunohistochemistry of liver samples. Typical hepatitis pathological change, such as spotty parenchymal cell degeneration, necrosis of hepatocytes and proliferation of fibrous connective tissue were observed during histopathological analysis. Analysis of HBsAg-positive serum with TEM revealed two morphologic forms, $20 \mathrm{~nm}$ and $40 \mathrm{~nm}$ sized particles, similar to small spherical and Danes particles of HBV. Observation of the ultrastructure of the liver also found HBV-like particles in the nucleus of hepatocytes.
\end{abstract}

Conclusion: Our research result implies that SHBV could be a causative agent of swine. The discovery of SHBV will unveil novel evolutionary aspects of hepatitis and provides new information for further hepadnavirus research.

\section{Background}

Viral hepatitis B remain a serious medical challenge worldwide [1]. A strong epidemiological relationship has been established between persistent hepatitis $\mathrm{B}$ virus (HBV) infection and hepatocellular carcinoma (HCC) [2]. HBV is one of the smallest enveloped animal viruses with a virion diameter of $42 \mathrm{~nm}$. But pleomorphic forms exist, including filamentous and spherical bodies lacking a core. As most hepadnaviruses, HBV will only replicate in specific hosts, and this makes experiments using in vitro methods very difficult.

Formerly, hepatitis B was called serum hepatitis. Detection of HBV infection involves serum or blood tests that detect either viral antigens (surface antigen $\mathrm{HBsAg}$ and e antigen $\mathrm{HBeAg}$ ) and antibodies (anti-HBs, anti-HBc, anti-HBe), known as HBV serological marker. $\mathrm{HBsAg}$ is most frequently used to screen for the presence of this infection, the presence of $\mathrm{HBeAg}$ in a host's serum is associated with much higher rates of

\footnotetext{
* Correspondence: sheruiping@126.com
'College of Veterinary Medicine, China Agricultural University, Beijing 100193,

* Correspondence: sheruiping@126.com
'College of Veterinary Medicine, China Agricultural University, Beijing 100193, China
}

(c) $2010 \mathrm{Li}$ et al; licensee BioMed Central Ltd. This is an Open Access article distributed under the terms of the Creative Commons Attribution License (http://creativecommons.org/licenses/by/2.0), which permits unrestricted use, distribution, and reproduction in any medium, provided the original work is properly cited. interpretation of these assays is complex.

$\mathrm{HBV}$ is the prototype member of a steadily growing family of hepadnaviruses which can be found in both mammals (orthohepadnaviruses) and birds (avihepadnaviruses). Orthohepadnaviruses have been identified so far in woodchucks (WHV), ground and arctic squirrels (GSHV, ASHV), and primates including woolly monkeys (WMHBV), orangutans, gorillas, and gibbons [3-8]. Avihepadnavirus has been reported in various duck species (DHBV), grey herons (HHBV), geese (GHBV), Ross's goose (RGHBV), storks (STHBV), and cranes (CHBV) [9-11]. The discovery of HBV-related viruses offers ample opportunities for in vivo studies of various animals with naturally occurring hepadnaviruses. This has been valuable in determining the mechanisms of hepadnavirus replication, pathogenesis of hepatocellular carcinoma (HCC), and for antiviral drug studies.

HBV-related hepadnaviruses in mammalian and avian species has been valuable in HBV studies. Like determining the mechanisms of hepadnavirus replication, pathogenesis of HCC, and antiviral drug studies [12]. 
However, most of the corresponding animals are difficult to handle in captivity or not easily available. Since none of the currently available animal models are ideal, the development of additional experimental animal models promises to provide answers for many HBV research questions [13].

Researchers have concentrated on a group of HBVlike viruses in domestic animals since 1985 [14]. Using human HBV diagnostic kits, a number of domestic animals are positive for HBV serological marker [15,16], electron microscope observed HBV-like virion in HBsAg positive serum of swine, Holstein, cattle, canine and sheep; even gene sequence highly homologous to HBV has been amplified [17-20]. Nevertheless, Up to the present time, none of these HBV-like viruses been systematically identified and related reports found only in China. Here we characterize the prevalence of HBV-like virus in swine which may provide an interesting model for comparative studies of liver pathology and cancer associated with chronic hepadnavirus infections.

\section{Results}

\section{Enzyme-linked immunosorbent assay}

To investigate the current prevalence of SHBV in swine herds, 416 samples of swine serum collected from 5 randomly selected farms in Beijing, China, were tested for HBV serological markers using a commercial ELISA kit. Briefly, overall prevalence of HBsAg was $24.8 \%$, and profoundly close to anti-HBs (25.0\%), while HBe and antiHBe was hardly detected $(0.5 \%$ and $0.7 \%)$, indicating no common antigen existed in HBe. The overall prevalence of anti-HBc was $63.9 \%$ (Fig. 1, Table 1).

\section{Histopathological analysis and Mallory's trichrome stain}

For swine CP74 and DX385, although obvious pathological changes were not observed at autopsy, pathological changes were observed under light microscope. Gross histopathological findings showed desmoplasia in hepatic lobules, infiltration of lymphocytes, hyperplasy of bile canaliculus, and fibrous tissue at the portal area (Fig. 2A and $2 \mathrm{~B}$ ). Severe fibrous connective tissue proliferation was observed by Mallory staining (Fig. 2C and 2D). In contrast, no obvious changes were found in liver tissues collected from swine CP59.

\section{Immunohistochemistry}

Immunohistochemical scanning of expression of viral antigens found that liver tissues from both swine contained HBsAg and HBcAg. Strong immunohistochemical signal was seen within hepatitis lesions. HBsAg was detected in the nucleus and cytoplasm of hepatocytes, while $\mathrm{HBcAg}$ was mainly distributed in the nucleus of hepatocytes. Necrosis as karyorrhexis, pyknosis and karyolisis was observed in immunohistochemically positive hepatocytes. This indicates that SHBV was pathogenic to swine, and replication of SHBV caused the necrosis of hepatocytes directly (Fig. 3A, B, C and 3D).

\section{Detection of viral particles in swine sera and liver cells by electron microscopy}

To obtain ultrastructural evidence for the presence of HBV-related viral particles in the swine sera containing $\mathrm{S}$ antigen, HBsAg-positive serum was collected, viral particles in the sera of infected swine were morphologically analyzed by electron microscopy and sera negative for HBsAg served as controls. Essentially, two types of particles closely resembled in size $(20 \mathrm{~nm}$ and $40 \mathrm{~nm})$ and morphology, like complete and empty viral particles of $\mathrm{HBV}$, were observed. However, it is puzzling that no tubular particles were seen. Particles were observed only in serum positive for $\mathrm{HBsAg}$, and the number of $40 \mathrm{~nm}$ particles was much more than expected (Fig. 4A). Ultrastructurally, HBV-like particles were observed in the nucleus of hepatocytes (Fig. 4B).

\section{Discussion}

Serological diagnosis of hepatitis B virus infection relies on a combination of qualitative assay results and different patterns are representative of acute or chronic disease in a carrier [21]. By examining the antigenantibody system, hepatitis B infection is diagnosed, the course of the disease is observed and treatment is monitored [22]. The screening of HBV serological markers in swine herds showed that nearly a quarter of swine have been infected. However, profiles in SHBV serology were quite different from human HBV (data not shown). Anti-HBc is found in all people infected with HBV, which can persist for many years and act as a lifelong marker of hepatitis B [23]. The high prevalence of anti$\mathrm{HBc}$ in swine $(63.9 \%)$ may indicate that these swine have a history of infection. Nevertheless, existence of anti-HBc as the only serological marker also may be the result of nonspecific cross-reaction with other agents [24].

Though hepadnaviruses are host specific, HBV infections also occur frequently in chimpanzee, gibbon and other ape populations in sub-Saharan Africa and SouthEast Asia where the HBV infection rate in apes was remarkably comparable to that of human population in these areas $[25,26]$. Scientists are concerned about the ability of HBV to cross species barriers. Large reservoirs of infection in apes may hamper ongoing attempts to permanently eradicate HBV infection from the human population through immunization [27].

The prevalence of HBV among human and the nonhuman primates maybe speed up the evolution process. Due to high error rate of the viral reverse transcriptase, and recombination among different genotypes or 


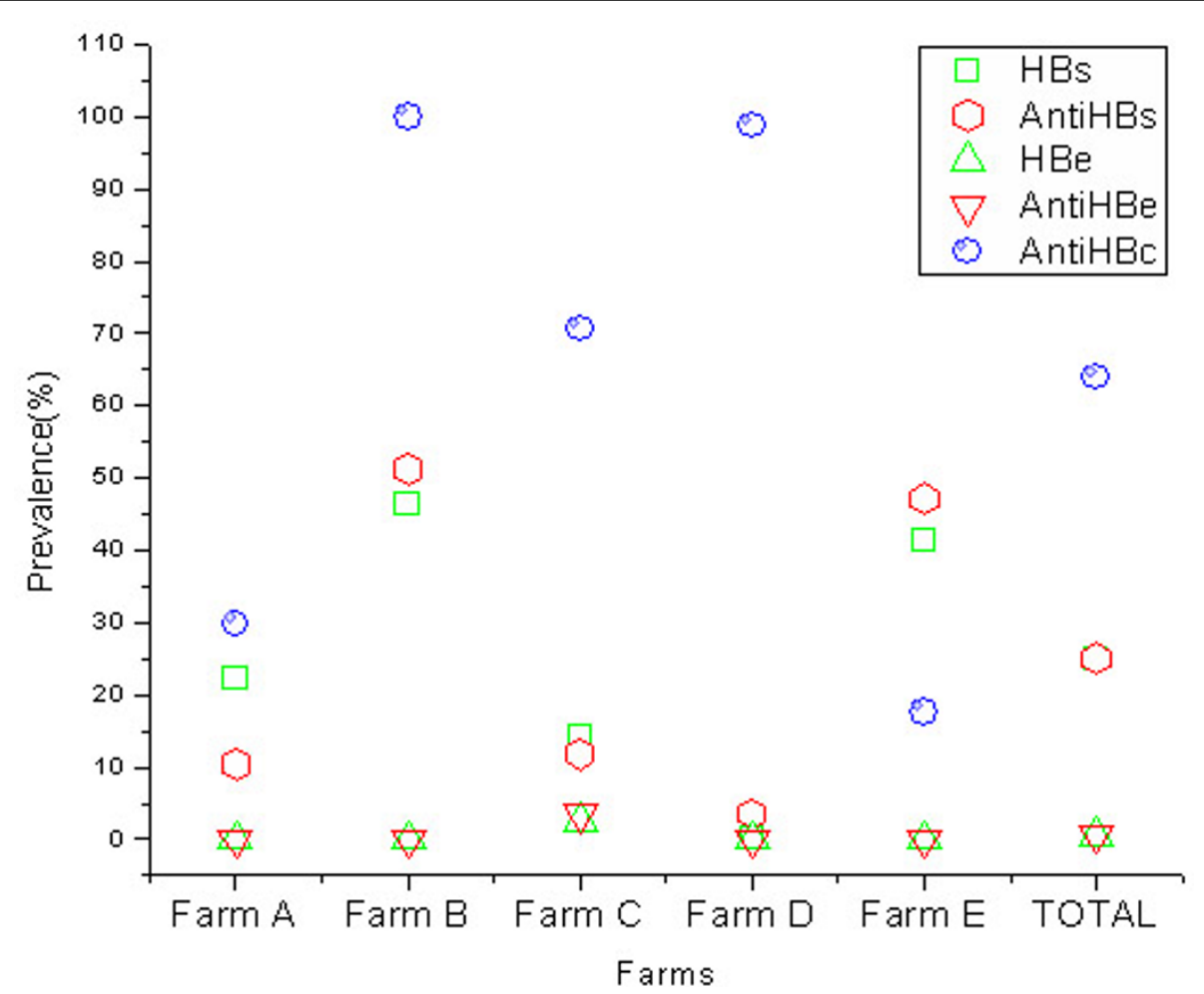

Figure 1 Prevalence of SHBV serological markers among 416 swine sera samples collected from five farms in Beijing, China. Scatter graphs showed that nearly a quarter of the swine have been infected by SHBV. Prevalence rates of HBs were close to anti-HBs, while HBeAg and anti-HBe were hardly detected.

hepadnavirus strains from human and nonhuman primates, the eight genotypes of HBV have further diverged into at least 24 subgenotypes, with certainly many more still to be identified [28]. Interspecies recombination events of HBV also occur among human and nonhuman primates [29], such as gibbons of different genera, chimpanzees, and birds of different subfamilies [25,30]. Interspecies recombination of hepadnaviruses from crossspecies hosts would provide a large variation in virus genomes, which would change pathogenecity and transmissibility, and expand the host range. Evidence for recombination of human and ape HBV variants demonstrates that human and nonhuman-associated HBV variants can indeed share hosts in nature [30]. Compared to nonhuman primates, domestic animals are in more contact with humans and the possibility of interspecies recombination is higher. Thus the discovery of SHBV will be beneficial to research of HBV evolution.

The lack of suitable in vitro infection systems and appropriate animal models has hampered the progress of HBV research, but progress has been made through the identification of avian and mammalian HBV-related viruses. However, none of these natural hosts are commonly used laboratory animals, and the expense and difficulty in handling these animals have limited their usage $[4,31,32]$. In fact, chimpanzees are the only animals fully permissive and well tested for HBV infection. Nonetheless, the limited availability and the high cost of keeping primates severely restricts their use in research [13]. Comparatively, pigs are widely used in medical

Table 1 Prevalence of SHBV serological markers among 416 swine sera samples collected from five farms

\begin{tabular}{|c|c|c|c|c|c|c|}
\hline & $\mathbf{n}$ & HBsAg, $n$ (\%) & HBsAb n (\%) & HBeAg, $n$ (\%) & Anti-HBe, n (\%) & Anti-HBc, n (\%) \\
\hline Farm A & 77 & $17(22.1)$ & $8(10.4)$ & $0(0)$ & $0(0)$ & $23(29.9)$ \\
\hline Farm B & 84 & 39 (46.4) & $43(51.2)$ & $0(0)$ & $0(0)$ & 84 (100) \\
\hline Farm C & 85 & $12(14.1)$ & $10(11.8)$ & $2(2.4)$ & $3(3.5)$ & $60(70.6)$ \\
\hline Farm D & 85 & $0(0)$ & $3(3.5)$ & $0(0)$ & $0(0)$ & $84(98.8)$ \\
\hline Farm E & 85 & $35(41.2)$ & $40(47.1)$ & $0(0)$ & $0(0)$ & 15 (17.6) \\
\hline Total & 416 & $103(24.8)$ & $104(25.0)$ & $2(0.5)$ & $3(0.7)$ & $266(63.9)$ \\
\hline
\end{tabular}




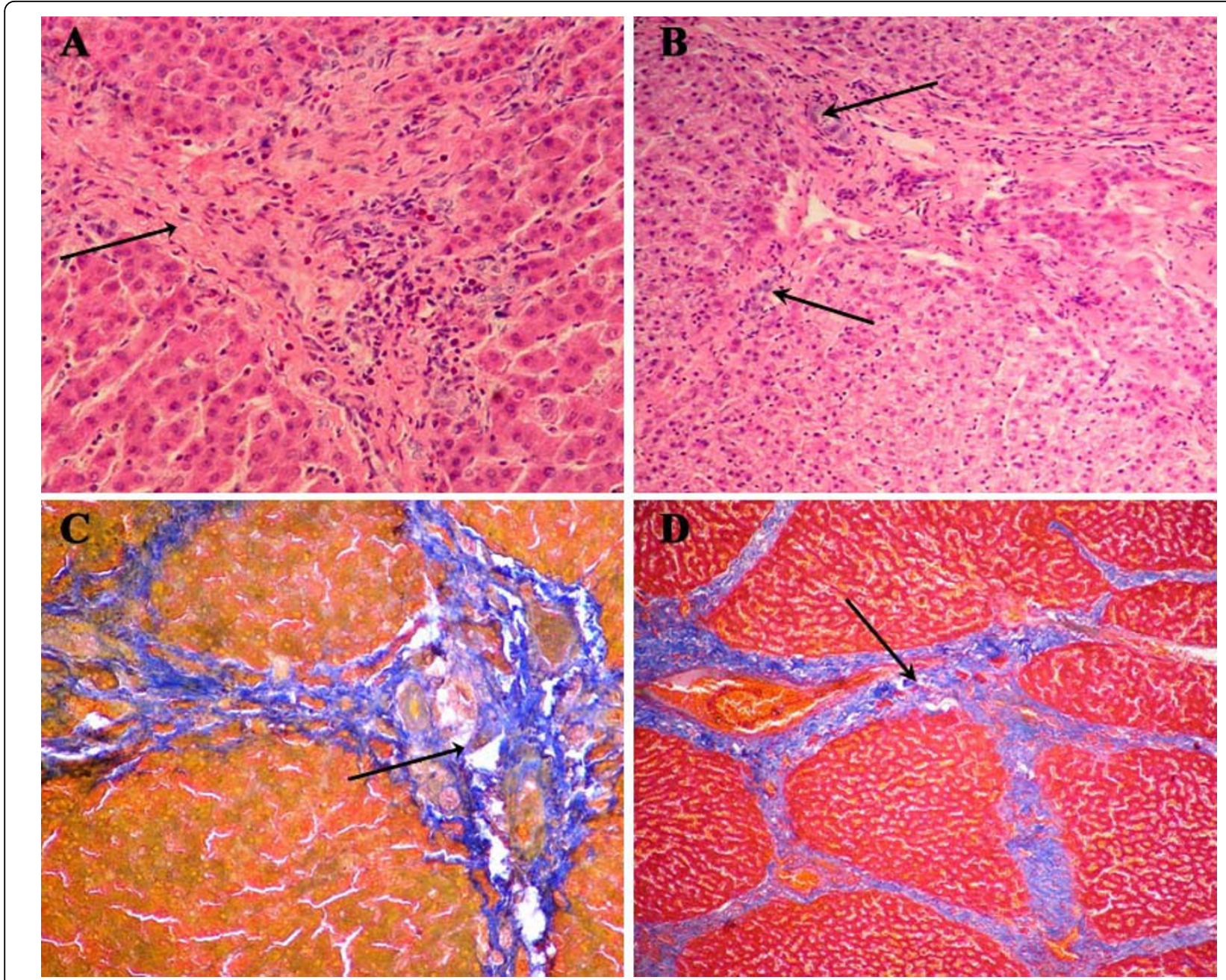

Figure 2 Results of histopathological analysis(A, B) and Mallory's trichrome stain(C, D). (A) desmoplasia between hepatic lobule (arrow), (B) infiltration of lymphocytes (down arrow), hyperplasy of bile canaliculus and fibrous tissue at portal area(up arrow), also coagulation necrosis and karyopyknosis of hepatocytes could be seen. Original magnification $\times 400$. (C, D) Showing proliferation of connective tissue between liver lobule (arrow). Mallory staining method, Original magnifications ×200. (A, C: liver sample from CP74; B, D: liver sample from DX385).

research and there are abundant in supply, since the available animal models are not ideal, the development of additional experimental animal systems is warranted, the finding of HBV in pigs will enhance our understanding of the virology and immunology of HBV infection and disease pathogenesis, including major sequelae like chronic hepatitis and hepatocellular carcinoma.

Of the 350 million to 400 million individuals worldwide infected with the hepatitis B virus (HBV), onethird reside in China, with 130 million carriers and 30 million chronically infected [33]. Even though a vaccination program for newborn babies has been in place since the $1990 \mathrm{~s}$, the incidence of hepatitis B is still increasing, from 21.9 in 100,000 people in 1990 to 53.3 in 100,000 in 2003. The reason for this increased HBV infection is unknown, because hepatitis B has no clear transmission routes in many people in China [34]. The identification of the SHBV strain confirms that a novel class of hepadnaviridae exists in swine populations. And thus brings about a lot of questions. Does these pigs infected by HBV? Does swine hepadnavirus exist? Does this virus related to the rising of hepatitis $B$ in human population? But before these questions could be answered, further studies are needed to elucidate the structure, assembly, genome organization and regulation of gene expression of this novel hepadnavirus.

\section{Methods}

\section{Swine and serum samples}

To determine the seroprevalence of SHBV infection in swine, 416 swine serum samples were collected from five randomly selected farms in Beijing, China. For serum collection, $5 \mathrm{~mL}$ of blood was collected from swine into dry tubes. After clotting and centrifugation, 


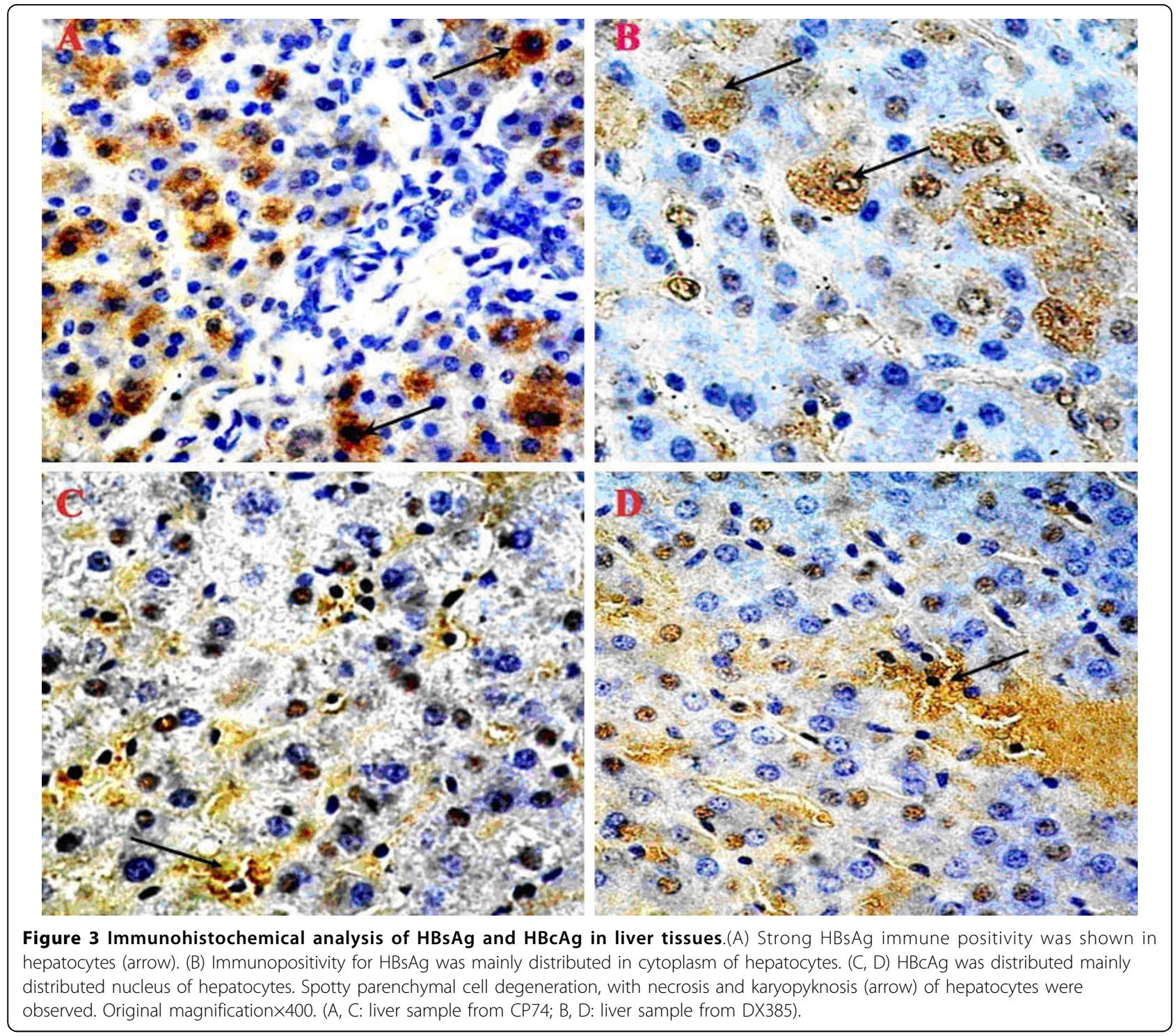

sera were separated and stored at $-20^{\circ} \mathrm{C}$ until use. Two swine positive for HBsAg (CP74:Boar, 7 month; DX385: Sow, 8.5 month) were sacrificed to determine the possible relationship of SHBV infection and histopathological changes in the liver. Another swine negative for all serological markers (CP59:Sow, 5 month) was sacrificed and served as a negative control.

\section{Serological analysis of hepatitis B virus markers}

All serum samples were screened for hepatitis B serological markers (anti-HBc, HBsAg, anti-HBs, HBeAg, and anti-HBe) with a commercial enzyme-linked immunosorbent assay (ELISA) kit (SIIC Kinghaw Biotech Co. Ltd., Beijing, China) according to the manufacturer's recommendations. The absorbance was determined at 450 nm (Multiscan Titertek MCC). Blank, negative and positive controls were included on each plate. Data were analyzed with the SPSS software for Windows (SPSS Inc., Chicago, USA) and a scatter graph was obtained by using OriginPro 7.5 (OriginLab Corporation, Northampton, MA, USA).

\section{Histopathology analysis and Mallory's trichrome stain}

Histopathological analysis was used to study the pathological characteristics of SHBV infection. In consideration of fibrosis is the pathological feature of chronic hepatitis, Mallory trichrome stain was used to study fibrous tissue proliferation in liver. Liver samples were collected and fixed in $2.5 \%(\mathrm{v} / \mathrm{v})$ glutaraldehyde-polyoxymethylene solution immediately after swine were sacrificed. The tissue samples were dehydrated and embedded in paraffin. Sections of $5-\mu \mathrm{m}$ thickness were then prepared for 


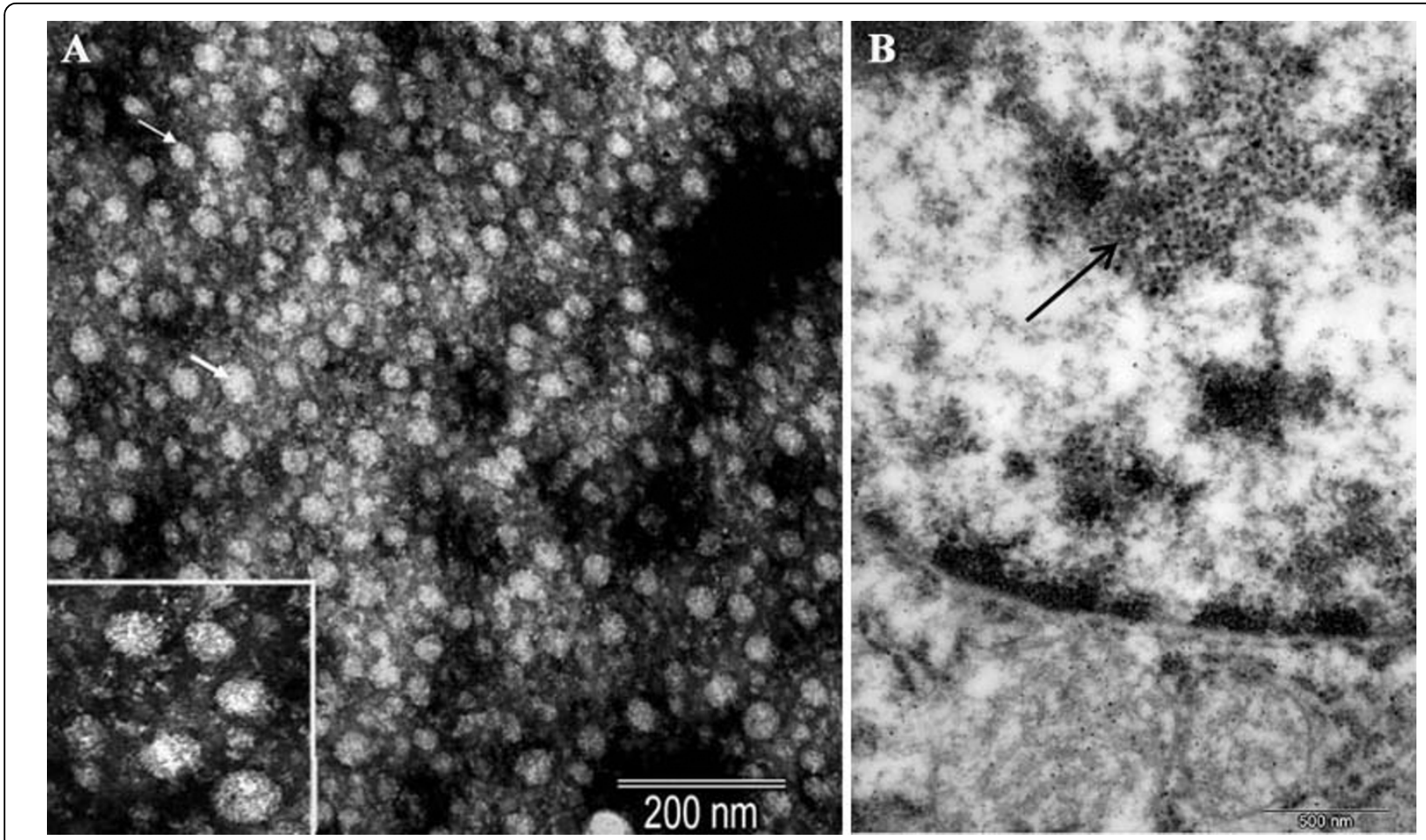

Figure 4 Viral particles in swine sera and hepatocytes revealed by electron microscopy. A: Electron micrographs of negatively stained SHBV particles from HBsAg positive serum. Two types of particles were observed which are similar in size (20 nm and $40 \mathrm{~nm})$ and morphology, like complete and empty viral particles of SHBV. B: Virus-like particles in the nucleus of hepatocytes (liver sample from DX385).

hematoxylin and eosin (H\&E), and Mallory trichrome stains. For Mallory's trichrome stain, paraffin sections were washed with distilled water and immersed in $3 \%$ dichromicum kalium for $5 \mathrm{~min}$, then in solution consisting of $0.1 \%$ acid fuchsin for $2 \mathrm{~min}$, and $0.5 \%$ aniline blue for $20 \mathrm{~min}$. Thereafter the slides were washed sequentially with distilled water, 95\% ethanol, and three changes of $100 \%$ xylene. After the xylene had evaporated, Cytoseal 60 mounting medium was applied, and the slides were coverslipped for examination under a microscope. All powdered stains used for Mallory stain were obtained from Sigma (Sigma Co., Beijing, China).

\section{Immunohistochemistry}

Serial paraffin sections $(5 \mu \mathrm{m})$ were prepared and kept at $37^{\circ} \mathrm{C}$ for more than 12 hours. The sections were immersed in three consecutive washings in xylol for $5 \mathrm{~min}$ to remove paraffin, and then hydrated through graded alcohol. Sections were incubated for $30 \mathrm{~min}$ and blocked with 3\% peroxide at room temperature for endogenous peroxidase ablation. The following steps were carried out in a moist chamber. Sections were incubated with blocking buffer (Zymed Laboratories Inc., San Diego, USA) containing 20\% normal goat serum (Gibco) and $80 \%$ PBS $(0.01 \mathrm{M}, \mathrm{pH} 7.4)$ at $37^{\circ} \mathrm{C}$ for $30 \mathrm{~min}$. After discarding the goat serum, sections were incubated in primary monoclonal antibodies against HBsAg and HBcAg (Zhongshan Golden Bridge Biotech Co. Ltd., Beijing, China) diluted in $\mathrm{PBS}$, for 2 hours at $37^{\circ} \mathrm{C}$. After rinsing for 3 times in PBS-T, sections were incubated with the goat anti-mouse IgG conjugated with HRP (Sigma) at $37^{\circ} \mathrm{C}$ for 1 hour and rinsed 3 times in PBS-T. The specimens were incubated with 3,3-diaminobenzidin (DAB; Zymed Laboratories Inc) at room temperature for $10 \mathrm{~min}$ in the dark. Finally, sections were stained with hematoxylin for 8 min after rinsing for 3 times in PBS-T, dehydrated, and mounted with neutral gums. Sections for the negative control group were prepared by the same steps as described above but with the HBsAg and HBcAg antibodies replaced by PBS.

\section{Detection of viral particles in swine sera and hepatocytes} by transmission electron microscopy

To obtain ultrastructural evidence for the presence of HBV-related viral particles in swine sera containing $S$ antigen, HBsAg-positive serums were collected and viral particles in sera of infected swine were morphologically analyzed by electron microscopy. Sera negative for HBsAg served as controls. Serum collected from three swine were centrifuged at $4000 \mathrm{rpm}$ for $10 \mathrm{~min}$, then $0.01 \mathrm{M}$ poly ethylene glycol 6000 (PEG6000) was added into the subsequent upper aqueous phase. After 
incubation overnight at $4^{\circ} \mathrm{C}$, the serum was centrifuged at 20,000 rpm for 1 hour, resuspended in PBS and stained for $1 \mathrm{~min}$ with $1 \%$ uranyl acetate. For the thin section study, the fixative used was $2.5 \%$ paraformaldehyde-glutaraldehyde in $0.1 \mathrm{M}$ cacodylate buffer ( $\mathrm{pH}$ 7.4). The sections were postfixed in $1 \% \mathrm{OsO}_{4}$ for 1 hour, and treated with $1 \%$ uranyl acetate, dehydrated in ethanol and embedded in Epon 812. Ultrathin sections were obtained using a routine method and stained with uranyl acetate and lead citrate. All electron micrographs were obtained with JEV1230 transmission electron microscope (JEOL Ltd., Tokyo, Japan) at $80 \mathrm{kV}$.

\section{Acknowledgements}

This work was supported by the National Natural Science Foundation of China (Grant No. 30871853) and the Yunnan Provincial Program for Introducing High-level Scientists (Grant No. 2009CI125).

The authors would like to thank Prof. Bin Wang (State Key Laboratory for Agro-Biotechnology, China Agricultural University) for permission and help in using the laboratory facilities.

\section{Author details}

'College of Veterinary Medicine, China Agricultural University, Beijing 100193, China. ${ }^{2}$ College of Animal Science and Technology, Yunnan Agricultural University, Kunming 650201, China. ${ }^{3}$ College of Agriculture, Hebei University of Engineering, Handan 056021, China.

\section{Authors' contributions}

WGL carried out the serological analysis of hepatitis B virus markers and drafted the manuscript. LQL carried out the Histopathology analysis and Mallory's trichrome stain. HY and JY carried out the immunohistochemical staining and transmission electron microscope investigations. RPS carried out the design of the study and revision of the manuscript. All authors read and approved the final manuscript.

\section{Competing interests}

The authors declare that they have no competing interests.

Received: 16 December 2009 Accepted: 17 March 2010 Published: 17 March 2010

\section{References}

1. Lai CL, Ratziu V, Yuen MF, Poynard T: Viral hepatitis B. The Lancet 2003, 362:2089-2094.

2. Buendia MA: Hepatitis B viruses and cancerogenesis. Biomed Pharmacother 1998, 52:34-43.

3. Summers J, Smolec JM, Snyder R: A virus similar to human hepatitis B virus associated with hepatitis and hepatoma in woodchucks. Proc Natl Acad Sci USA 1978, 75:4533-4537.

4. Testut P, Renard CA, Terradillos O, Vitvitski-Trepo L, Tekaia F, Degott C, Blake J, Boyer B, Buendia MA: A new hepadnavirus endemic in arctic ground squirrels in Alaska. J Virol 1996, 70:4210-4219.

5. Lanford RE, Chavez D, Brasky KM, Burns RB lii, Rico-Hesse R: Isolation of a hepadnavirus from the woolly monkey, a new World primate. Proc Nat Acad Sci USA 1998, 95:5757-5761.

6. Warren KS, Heeney JL, Swan RA, Heriyanto, Verschoor EJ: A new group of hepadnaviruses naturally infecting orangutans (Pongo pygmaeus). J Virol 1999, 73:7860-7865.

7. Linnemann CC Jr, Kramer LW, Askey PA: Familial clustering of hepatitis B infections in gorillas. AM J Epidemiol 1984, 119:424-430.

8. Noppornpanth S, Haagmans BL, Bhattarakosol P, Ratanakorn P, Niesters HGM, Osterhaus ADME, Poovorawan Y: Molecular epidemiology of gibbon hepatitis B virus transmission. J Gen Virol 2003, 84:147-155.

9. Prassolov A, Hohenberg H, Kalinina T, Schneider C, Cova L, Krone O, Frolich K, Will H, Sirma H: New Hepatitis B Virus of Cranes That Has an Unexpected Broad Host Range. J Virol 2003, 77:1964-1976.
10. Pult I, Netter HJ, Bruns M, Prassolov A, Sirma H, Hohenberg H, Chang SF, FrÖlich K, Krone O, Kaleta EF, Will H: Identification and analysis of a new hepadnavirus in white storks. Virology 2001, 289:114-128.

11. Funk A, Mhamdi M, Will H, Sirma H: Avian hepatitis B viruses: Molecular and cellular biology, phylogenesis, and host tropism. World J Gastroenterol 2007, 13:91-103

12. Olive DS, Konishi M, Wu GY: Cell culture and animal models for human viral hepatitis. Hepatol Res 2004, 28:61-67.

13. Dandri M, Volz TK, Lutgehetmann M, Petersen J: Animal models for the study of HBV replication and its variants. J Clin Virol 2005, 34:S54-S62.

14. Qifeng $X$ : Experimental infection of chickens with hepatitis B virus. Chinese Journal of Nature 1985, 9:238-239.

15. She RP, Li WG, Wang YH, Liu L, Hu YX, Xu JC, Bao HH, Wang DC: Viral Hepatitis: A Dangerous Zoonosis. Sci Technol Rev 2007, 25:44-52.

16. $\mathrm{Xu} \mathrm{YW,} \mathrm{Chu} \mathrm{X:} \mathrm{Study} \mathrm{progress} \mathrm{on} \mathrm{HBV-like} \mathrm{virus} \mathrm{in} \mathrm{animal.} \mathrm{Chinese} \mathrm{J} \mathrm{Prev}$ Vet Sci Technol 1993, 23:16-20.

17. Shao XA, Xu W, Wang Y, Xiong SD: HBsAg-like protein detected in the bovine serum. Fudan Univ J Med Sci 2004, 31:585-587, +596..

18. Din Z, Wang CY, jin NY, Zou XH, Bai L, Nie Y, Liu CG: Hereditary variation in $\mathrm{S}$ gene sequence of hepatitis B virus from canine. Chinese J Prev Vet Med 2003, 25:24-28.

19. Din Z, Jin NY, Chen ZW, Zou XH, Yang HSO: S Gene Sequence Comparison between the HBV like virus from chicken and human HBV. Chinese J Prev Vet Sci Technol 1999, 19:18-21.

20. Din Z, Jin NY, Chen CF, Zou XH, Wang CY: Study on S Gene Sequence Homologous Analysis between the Hepatitis B Virus from Sheep and Human. Progress in Veterinary Medicine 2001, 22:54-58.

21. Salassa B, Daziano E, Bonino F, Lavarini C, Smedile A, Chiaberge E, Rosina F, Rossana Brunetto M, Pessione E, Spezia C, et al: Serological diagnosis of hepatitis B and delta virus (HBV/HDV) coinfection. J Hepatol 1991, 12:10-13.

22. Badur S, Akgun A: Diagnosis of hepatitis B infections and monitoring of treatment. J Clin Virol 2001, 21:229-237.

23. Tseliou P, Spiliotakara A, Dimitracopoulos GO, Christofidou M: Detection of hepatitis $B$ virus DNA in blood units with anti-HBC as the only positive serological marker. Haematologia 2000, 30:159-165.

24. Sanchez-Quijano A, Jauregui Jl, Leal M, Pineda JA, Castilla A, Abad MA, Civeira MP, Garcia de Pesquera F, Prieto J, Lissen E: Hepatitis B virus occult infection in subjects with persistent isolated anti-HBc reactivity. $J$ Hepatol 1993, 17:288-293.

25. Yang J, Xi Q, Deng R, Wang J, Hou J, Wang X: Identification of interspecies recombination among hepadnaviruses infecting crossspecies hosts. J Med Virol 2007, 79:1741-1750.

26. Starkman SE, MacDonald DM, Lewis JCM, Holmes EC, Simmonds P: Geographic and species association of hepatitis B virus genotypes in non-human primates. Virology 2003, 314:381-393.

27. Makuwa M, Souquière S, Clifford SL, Mouinga-Ondeme A, Bawe-Johnson M, Wickings EJ, Latour S, Simon F, Roques P: Identification of hepatitis B virus genome in faecal sample from wild living chimpanzee (Pan troglodytes troglodytes) in Gabon. J Clin Virol 2005, 34:S83-S88.

28. Schaefer S: Hepatitis B virus taxonomy and hepatitis B virus genotypes. World J Gastroenterol 2007, 13:14-21.

29. Magiorkinis EN, Magiorkinis GN, Paraskevis DN, Hatzakis AE: Re-analysis of a human hepatitis $B$ virus (HBV) isolate from an East African wild born Pan troglodytes schweinfurthii: Evidence for interspecies recombination between HBV infecting chimpanzee and human. Gene 2005, 349:165-171.

30. Simmonds $P$, Midgley $S$ : Recombination in the genesis and evolution of hepatitis B virus genotypes. J Virol 2005, 79:15467-15476.

31. Menne $S$, Cote PJ: The woodchuck as an animal model for pathogenesis and therapy of chronic hepatitis B virus infection. World J Gastroenterol 2007, 13:104-124.

32. Feitelson MA, DeTolla $L J$, Zhou XD: A chronic carrierlike state is established in nude mice injected with cloned hepatitis B virus DNA. J Virol 1988, 62:1408-1415.

33. Liu J, Fan D: Hepatitis B in China. The Lancet 2007, 369:1582-1583.

34. Wang XJ, Zhang RZ, Hu YS, F LX: Analysis on epidemic status of viral hepatitis in China: the report from Chinese Center for Disease Control and Prevention. Dis Surveillance 2004, 19:290-292.

doi:10.1186/1743-422X-7-60

Cite this article as: Li et al:: Prevalence of a virus similar to human hepatitis B virus in swine. Virology Journal 2010 7:60. 